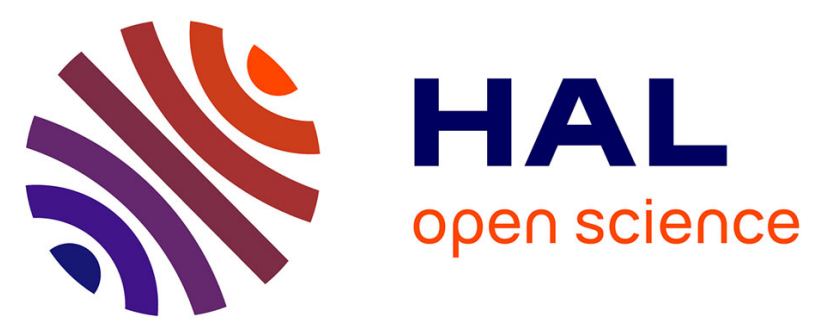

\title{
3D complex modulus tests on bituminous mixture with sinusoidal loadings in tension and/or compression
}

Quang Tuan Nguyen, Hervé Di Benedetto, Cédric Sauzeat, Mai Lan Nguyen, Thi Thanh Nhan Hoang

\section{- To cite this version:}

Quang Tuan Nguyen, Hervé Di Benedetto, Cédric Sauzeat, Mai Lan Nguyen, Thi Thanh Nhan Hoang. 3D complex modulus tests on bituminous mixture with sinusoidal loadings in tension and/or compression. Materials and structures, 2016, 50, pp.98. 10.1617/s11527-016-0970-x . hal-01582496

\section{HAL Id: hal-01582496 \\ https://hal.science/hal-01582496}

Submitted on 6 Sep 2017

HAL is a multi-disciplinary open access archive for the deposit and dissemination of scientific research documents, whether they are published or not. The documents may come from teaching and research institutions in France or abroad, or from public or private research centers.
L'archive ouverte pluridisciplinaire HAL, est destinée au dépôt et à la diffusion de documents scientifiques de niveau recherche, publiés ou non, émanant des établissements d'enseignement et de recherche français ou étrangers, des laboratoires publics ou privés. 


\title{
3D complex modulus tests on bituminous mixture with sinusoidal loadings in tension and/or compression
}

\author{
Quang Tuan Nguyen ${ }^{1}$ - Hervé Di Benedetto ${ }^{2}$ - Cédric Sauzéat ${ }^{2}$ - Mai Lan \\ Nguyen $^{3}$ - Thi Thanh Nhan Hoang ${ }^{1}$ \\ ${ }^{1}$ University of Transport and Communications, Hanoi, Vietnam \\ quangtuan.nguyen@utc.edu.vn, ttnhan.hoang@utc.edu.vn \\ ${ }^{2}$ LGCB \& LTDS (UMR CNRS 5513), University of Lyon /Ecole Nationale des \\ Travaux Publics de l'Etat (ENTPE), Vaulx-en-Velin Cedex, France \\ herve.dibenedetto@entpe.fr, cedric.sauzeat@entpe.fr \\ ${ }^{3}$ French Institute of science and technology for transport, development and \\ Networks, IFSTTAR, Nantes, France \\ mai-lan.nguyen@ifsttar.fr
}

\begin{abstract}
This paper presents an investigation into 3Dim viscoelastic behaviour of bituminous mixture. Complex modulus tests were performed at ENTPE laboratory on cylindrical samples, for three different modes of sinusoidal loading: only tension, only compression and tensioncompression. Stress-controlled mode was used for cyclic tension tests and cyclic compression tests whereas cyclic tension-compression tests were conducted in strain-controlled mode. For all loading conditions, the strain amplitude of sinusoidal cyclic loadings is less than $60 \mu \mathrm{m} / \mathrm{m}$. Complex modulus $\mathrm{E}^{*}$ and complex Poisson's ratio $v^{*}$ were measured at five temperatures ranging from $1{ }^{\circ} \mathrm{C}$ to $30^{\circ} \mathrm{C}$ and at six frequencies ranging from $0.03 \mathrm{~Hz}$ to $10 \mathrm{~Hz}$. The results indicated that complex moduli are the same for the 3 modes of loading for average and low temperatures. Rather small differences were obtained between complex modulus values obtained from the three types of loading for higher temperatures. These differences could be explained by nonlinearity (modulus value depending on strain level) and accumulated strain existing only for tension and compression type tests. No noticeable differences in complex Poisson's ratio could be obtained from the 3 modes of loading.
\end{abstract}

Keywords: bituminous mixture, modes of loading, complex modulus, complex Poisson's ratio, viscoelasticity

\section{Introduction}

The three dimension (3D) viscoelastic isotropic behaviour can be characterized by complex modulus $E^{*}$ and complex Poisson's ratio $v^{*}$. In order to obtain these parameters, complex modulus tests are usually conducted under sinusoidal cyclic 
loadings at different temperatures and frequencies. Some authors performed the one dimension (1D) complex modulus tests on bituminous mixtures and compared obtained results when using different types of test, specimen geometries or sizes of specimen [1-3]. Kallas [4], Khanal and Mamlouk [5] indicated differences in complex modulus $\mathrm{E}^{*}$ (norm and phase angle) obtained from different loading modes (quasi-static compressive, quasi-static tensile, cyclic tension, cyclic compression, cyclic tension-compression). The effect of strain (stress) amplitude was also studied and reported in references. When small strain amplitude (less than $100 \mu \mathrm{m} / \mathrm{m}$ ) is applied, the behaviour of bituminous mixtures can be considered as linear viscoelastic (LVE) as a first approximation [6-8]. From experimental results, Nguyen QT et al. [9] observed nonlinearity of bituminous mixtures even at small strain amplitudes $(<125 \mu \mathrm{m} / \mathrm{m})$, which affects both norm and phase angle of complex modulus. They also showed that that viscoelastic linearity limit (strain amplitude corresponding to a decrease of $5 \%$ of the norm of complex modulus) varies with equivalent temperature-frequency couples. Many researches confirmed that Time Temperature Superposition Principle (TTSP) can be applied with good approximation to bituminous materials, in the small strain domain (strain amplitudes lower than $100 \mu \mathrm{m} / \mathrm{m}$ ) [10-15] even considering wave propagations [16-18] or in the nonlinear domain (strain up to some percent) [9, 19-23]. TTSP was showed to be also valid in 3 dimensions [24-27].

In this paper, complex modulus tests were performed in order to study $3 \mathrm{D}$ viscoelastic behaviour of bituminous mixture under three different modes of sinusoidal loading: tension, compression and tension-compression loading. This research was mainly initiated to answer the often raised question of the existence or not of different moduli (and more widely different behaviour) in tension and compression for these materials.

Five temperatures (from $1{ }^{\circ} \mathrm{C}$ to $30^{\circ} \mathrm{C}$ ) and at six frequencies (from $0.03 \mathrm{~Hz}$ to 10 $\mathrm{Hz}$ ) were used. The differences in complex modulus $\mathrm{E}^{*}$ and complex Poisson's ratio $v^{*}$ (both norm and phase angle) obtained from the three loading paths are discussed. It should be noted that cyclic tension-compression (TC) tests were conducted in strain-controlled mode whereas cyclic tension $(\mathrm{T})$ tests and cyclic compression (C) tests were performed in stress-controlled mode having a nil minimal (or maximal) stress value. Thus, although the applied strain amplitude of sinusoidal cyclic loadings is rather small (less than $60 \mu \mathrm{m} / \mathrm{m}$ ), accumulated axial 
and radial strains up to some $10^{3} \mu \mathrm{m} / \mathrm{m}$ could be reached in $\mathrm{T}$ and $\mathrm{C}$ types loading. Validity of the TTSP for $\mathrm{E}^{*}, v^{*}$ is also analysed.

\section{Experimental programme}

\subsection{Tested material and specimens}

Bituminous mixture is a 0/14 mm aggregate grading dosed at 6\% (aggregate weight) with a 35/50 penetration grade bitumen. The cylindrical specimens have a diameter of $74 \mathrm{~mm}$ and a height of $140 \mathrm{~mm}$. The specimens were cored and sawn from slabs made with a French (LPC) wheel compactor, according to the European standard [28]. The air void of tested specimen presented in this paper is $2.5 \%$.

\subsection{Test equipment}

The loading is applied on the cylindrical specimen along axial direction " 1 " using a hydraulic press associated with a temperature-controlled chamber. Three extensometers are used to measure the axial strain in the middle part of the specimen (Fig. 1). These three extensometers having an initial length of $75 \mathrm{~mm}$ are positioned at $120^{\circ}$ around the sample. The average of three extensometers is used for analysis of results. Four non-contact sensors are used to measure the radial strains in two radial perpendicular directions (direction 2 and direction 3 ) (Fig. 1). For each direction, two non-contact sensors aim at two targets which are fixed oppositely on a sample diameter. Direction 1, 2 and 3 correspond to the plate compactor wheel rolling direction, vertical direction and transverse direction, respectively. A sensor PT100 fixed at the surface of the sample measures the temperature during the test (Fig.1).

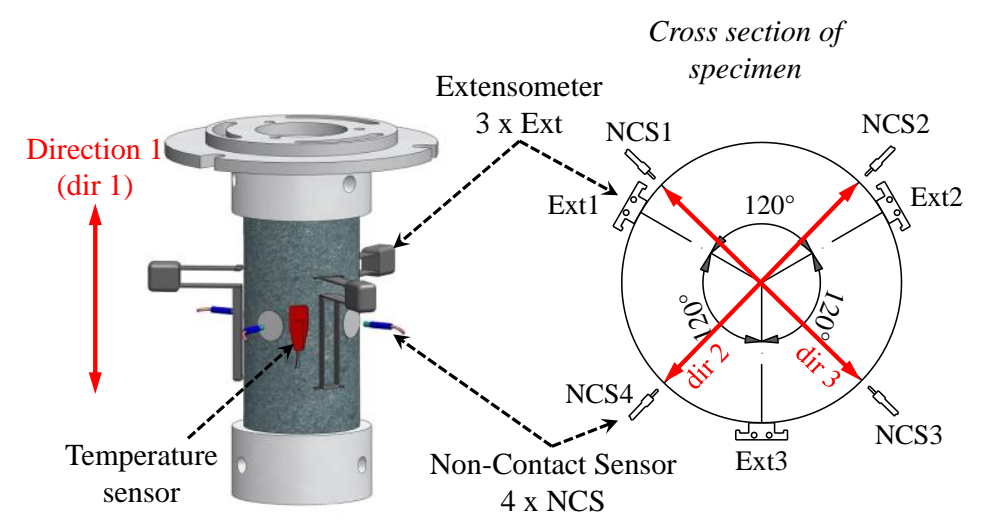


Fig.1 Cylindrical specimen and devices used to measure axial strain and radial strains

\subsection{Complex modulus tests}

Complex modulus tests were performed at six frequencies $\mathrm{f}(0.03 \mathrm{~Hz}, 0.1 \mathrm{~Hz}, 0.3$ $\mathrm{Hz}, 1 \mathrm{~Hz}, 3 \mathrm{~Hz}, 10 \mathrm{~Hz})$ and five temperatures $\mathrm{T}_{0}\left(1.4^{\circ} \mathrm{C}, 11.1^{\circ} \mathrm{C}, 15.8^{\circ} \mathrm{C}, 20.4^{\circ} \mathrm{C}\right.$, $29.9^{\circ} \mathrm{C}$ ). At each given temperature, three different modes of sinusoidal loading (tension (T), compression (C) and tension-compression (T/C) loadings) were applied on the same specimen following the procedure indicated in Fig.2.

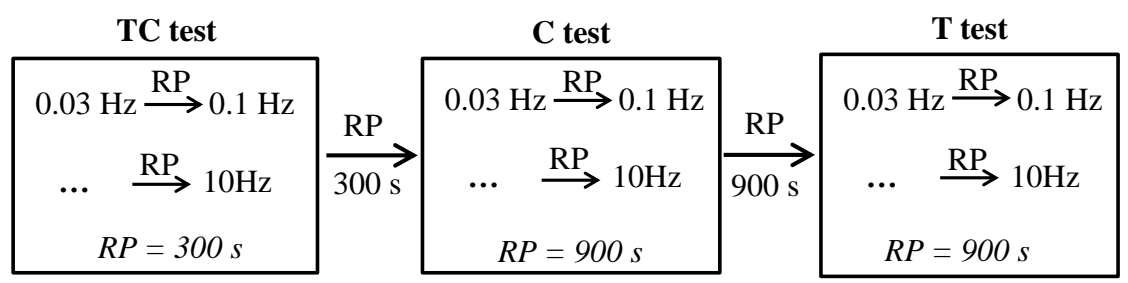

RP: Rest Period $\left(\sigma_{1}=0\right)$

Fig.2 Procedure of test at a fixed temperature

Stress and strains measurements were collected with a minimum of 150 data points for each cycle. Cyclic tension-compression (C/T) tests were conducted in strain-controlled mode (equation 1) whereas cyclic tension ( $\mathrm{T}$ ) tests and cyclic compression (C) tests were performed in stress-controlled mode (equation 6). A rest period of 300 seconds ( 900 seconds) was considered between each loading phase in strain-controlled mode (resp. in stress-controlled mode) between two successive frequencies (Fig. 2). The number of performed cycles (N) at each temperature and frequency couple, which is always less than 80 , depends on frequency, as indicated in Table 1. As a small number of cycles is applied, heating, reversible phenomena and fatigue damage on the sample can be considered as negligible [29-31]. The applied strain amplitude of sinusoidal cyclic loadings is controlled to be about $50 \mu \mathrm{m} / \mathrm{m}$. It is always smaller than $60 \mu \mathrm{m} / \mathrm{m}$. To avoid transient effects [32], the first 2-3 cycles were not considered in the analysis.

Table 1 Number of applied cycles and considered cycles for analysis at each frequency

\begin{tabular}{|c|c|c|c|c|c|c|}
\hline $\mathrm{f}(\mathrm{Hz})$ & 0.03 & 0.1 & 0.3 & 1 & 3 & 10 \\
\hline Number of applied cycles & 10 & 20 & 20 & 30 & 40 & 80 \\
\hline Considered cycles for $\mathrm{E}^{*}$ analysis & $3-4$ & $3-6$ & $3-6$ & $3-8$ & $3-10$ & $5-12$ \\
\hline Considered cycles for ${ }^{*}$ analysis & $3-10$ & $3-20$ & $3-20$ & $3-30$ & $3-40$ & $5-80$ \\
\hline
\end{tabular}


Fig. 3 shows an example of axial stress, axial strain and radial strains

measurements for $\mathrm{TC}$ test at $\mathrm{T}_{0}=20.4{ }^{\circ} \mathrm{C}$ and $\mathrm{f}=0.1 \mathrm{~Hz}$. In strain-controlled mode (tension/compression (TC) test), sinusoidal axial strain $\left(\varepsilon_{1}\right)$ (average of three extensometers) is used for monitoring. Sinusoidal curves were fitted to the experimental data (axial strain in $\varepsilon_{1}$, radial strains $\varepsilon_{2}, \varepsilon_{3}$ and axial stress $\sigma_{1}$ ) and used to calculate the norm and phase angle of complex modulus $\left(\mathrm{E}^{*}\right)$ and complex Poisson's ratios $\left(v_{2}{ }^{*}\right.$ and $\left.v_{3}{ }^{*}\right)$ using equations 1 to 5 . In these equations, $\varepsilon_{01}, \varepsilon_{02}, \varepsilon_{03}$ and $\sigma_{01}$ are axial strain amplitude, radial strain amplitude in directions 2 and 3 and axial stress amplitude, respectively. $\phi_{\mathrm{E}}$ is the phase angle between axial strain and axial stress, and $\phi_{v 2}, \phi_{v 3}$ are the phase angles between the axial strain and the opposite of radial strains in directions 2 and $3 .\left|E^{*}\right|,\left|v_{2}{ }^{*}\right|$ and $\left|v_{3}{ }^{*}\right|$ are the norms of complex modulus and complex Poisson's ratios. $\mathrm{j}$ is the complex number defined by $j^{2}=-1$.

$$
\begin{aligned}
& \varepsilon_{1}(\mathrm{t})=\varepsilon_{01} \sin (\omega \mathrm{t}) \\
& \sigma_{1}(\mathrm{t})=\sigma_{01} \sin \left(\omega \mathrm{t}+\phi_{\mathrm{E}}\right) \\
& \varepsilon_{\mathrm{i}}(\mathrm{t})=-\varepsilon_{0 \mathrm{i}} \sin \left(\omega \mathrm{t}+\phi_{v \mathrm{i}}\right) \quad(\mathrm{i}=2,3) \\
& \mathrm{E}^{*}=\frac{\sigma_{01}}{\varepsilon_{01}} \mathrm{e}^{\mathrm{j} \phi_{\mathrm{E}}}=\left|\mathrm{E}^{*}\right| \mathrm{e}^{\mathrm{j} \phi_{\mathrm{E}}} \\
& v_{i}^{*}=\frac{\varepsilon_{0 \mathrm{i}}}{\varepsilon_{01}} \mathrm{e}^{\mathrm{j} \phi_{v i}}=\left|v_{i}^{*}\right| \mathrm{e}^{\mathrm{j} \phi_{v i}} \quad(\mathrm{i}=2,3)
\end{aligned}
$$

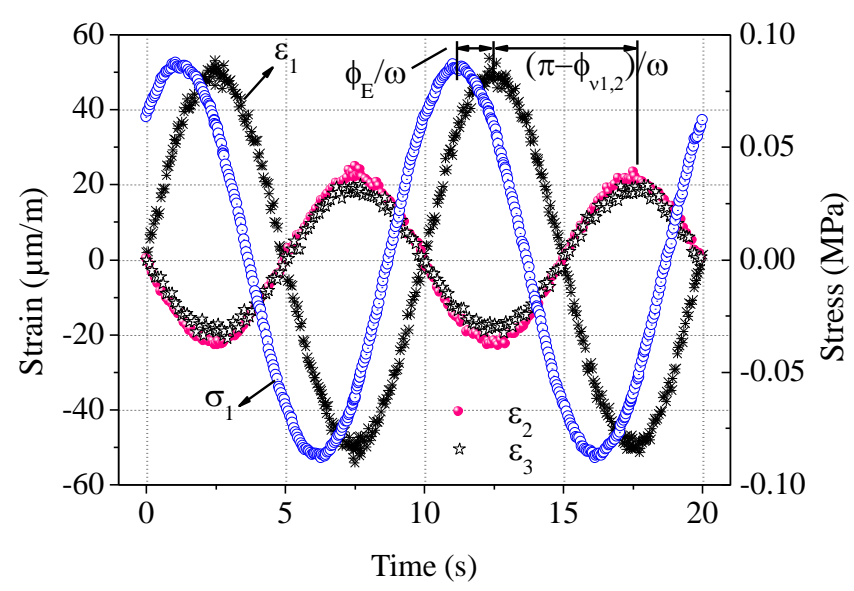

Fig. 3 Example of stress and strains measurements (TC test in strain-controlled mode, 2 cycles at $\mathrm{f}$ $=0.1 \mathrm{~Hz}$ and $\mathrm{T}=20.4{ }^{\circ} \mathrm{C}$ )

Fig. 4 shows an example of axial stress, axial strain and radial strains measurements in Tension ( $\mathrm{T}$ ) test at $\mathrm{T}_{0}=20.4{ }^{\circ} \mathrm{C}$ and $\mathrm{f}=0.1 \mathrm{~Hz}$. For stresscontrolled mode (Tension (T) tests and Compression (C) tests), haversine compression (or tension) loading stress is applied on the specimen. Equations 6 to 
8 are used to fit measured stress and strain values. In these equations, $\tau$ varies from 0 to $2 / \mathrm{f}$ (two cycles). The parameters $\sigma_{01}, \alpha_{i}(\mathrm{~N}), \varepsilon^{\mathrm{p}_{i}}(\mathrm{~N}), \varepsilon_{0 \mathrm{i}}(\mathrm{N}), \tau$ are presented in Fig. 4 and Fig. 5. As a convention, tension axial stress and extension axial strain are chosen as positive. $\varepsilon^{\mathrm{p}_{i}}(\mathrm{~N})$ and $\alpha_{\mathrm{i}}(\mathrm{N})(\mathrm{i}=1,2$ or 3$)$ characterise the accumulated strain and the strain rate at cycle $\mathrm{N}$, respectively. As accumulated deformation should not be considered, complex modulus $\mathrm{E}^{*}$ and complex Poisson's ratios $v_{2}{ }^{*}$ and $v_{3}{ }^{*}$ are obtained from the sinusoidal components of axial stress, axial strain and radial strains (i.e., the $2^{\text {nd }}$ right term of equation 6 and the $3^{\text {rd }}$ right term of equations 7 and 8), using equations 4 and 5.

$$
\begin{aligned}
& \sigma_{1}(\mathrm{t})=\sigma_{01}+\sigma_{01} \sin \left(\omega \mathrm{t}+\phi_{\mathrm{E}}\right) \\
& \varepsilon_{1}(\mathrm{t})=\varepsilon_{1}(\mathrm{~N}, \tau)=\alpha_{1}(\mathrm{~N}) \tau+\varepsilon^{\mathrm{p}_{1}}(\mathrm{~N})+\varepsilon_{01}(\mathrm{~N}) \sin (\omega \tau) \\
& \varepsilon_{i}(\mathrm{t})=\varepsilon_{\mathrm{i}}(\mathrm{N}, \tau)=\alpha_{\mathrm{i}}(\mathrm{N}) \tau+\varepsilon^{\mathrm{p}_{i}}(\mathrm{~N})-\varepsilon_{0 i}(\mathrm{~N}) \sin \left(\omega \tau+\phi_{v i}\right)(\mathrm{i}=2,3) \\
& \text { with } \mathrm{t}=\mathrm{N} / \mathrm{f}+\tau \text { and } \tau \text { varies from } 0 \text { to } 2 / \mathrm{f}(\mathrm{two} \text { cycles })
\end{aligned}
$$

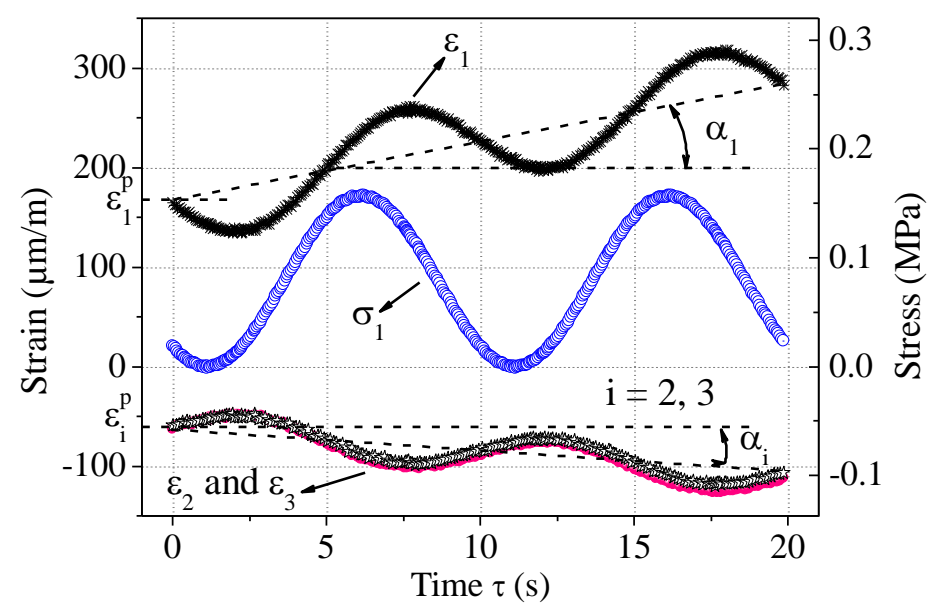

Fig.4 Example of stress and strains measurements ( $\mathrm{T}$ test in stress-controlled mode, 2 cycles at $\mathrm{f}=$ $0.1 \mathrm{~Hz}$ and $\mathrm{T}=20.4^{\circ} \mathrm{C}$ ) 

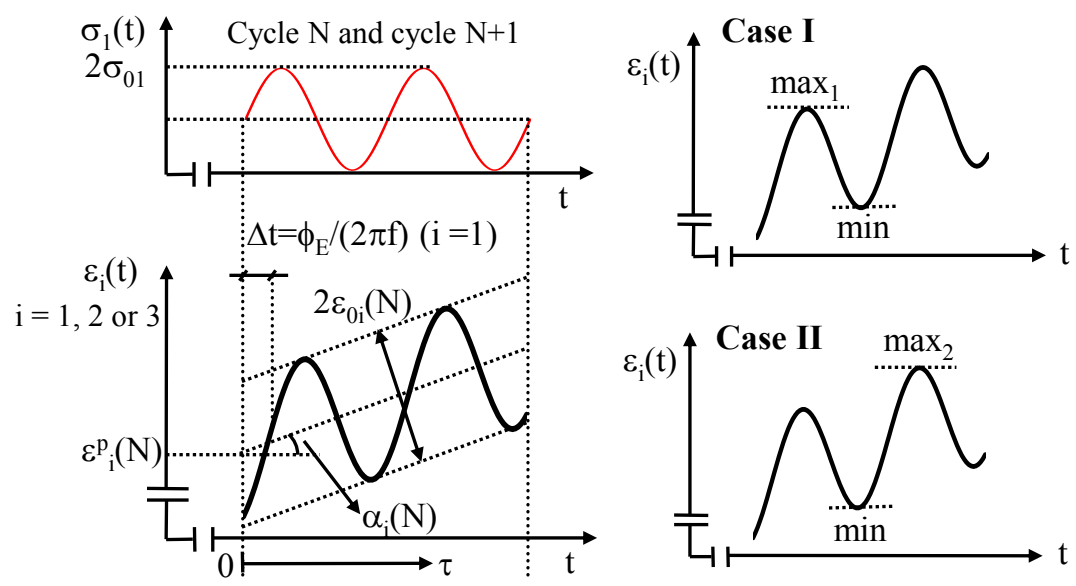

Fig.5 Evolution with time of the stress and strain in stress-controlled mode (schematic representation): parameters used in the analysis

\section{Analysis of the results}

\subsection{Complex modulus and complex Poisson's ratios}

Fig. 6 presents the results of $\left|\mathrm{E}^{*}\right|$ and $\left|v_{2}{ }^{*}\right|$ measurements with the number of applied cycles, obtained at $20.4^{\circ} \mathrm{C}, 3 \mathrm{~Hz}$ and from the 3 loading modes. The 2 first cycles (4 first cycles at $10 \mathrm{~Hz}$ ) (Table 1), corresponding to an adaptation non stationary phase [32], were not taken into account for the analysis. It can be seen on this example (presented in Fig. 6) that the norm of complex modulus slightly decreases in case of TC test and slightly increases in case of $\mathrm{T}$ test and $\mathrm{C}$ test. The norms of complex modulus are "close" for the three loading modes. There is no clear tendency observed in change of complex Poisson's ratio $\left|v_{2}{ }^{*}\right|$ that remains rather constant and very close for the 3 modes of loading. For the analysis presented further, the complex modulus $E^{*}$ and the complex Poisson's ratio $v^{*}$ is considered as the average value from the few first cycles. The cycles taken into account for calculation of $\mathrm{E}^{*}$ and $v^{*}$ depend on frequency and are indicated in Table 1 and in Fig. 6. 


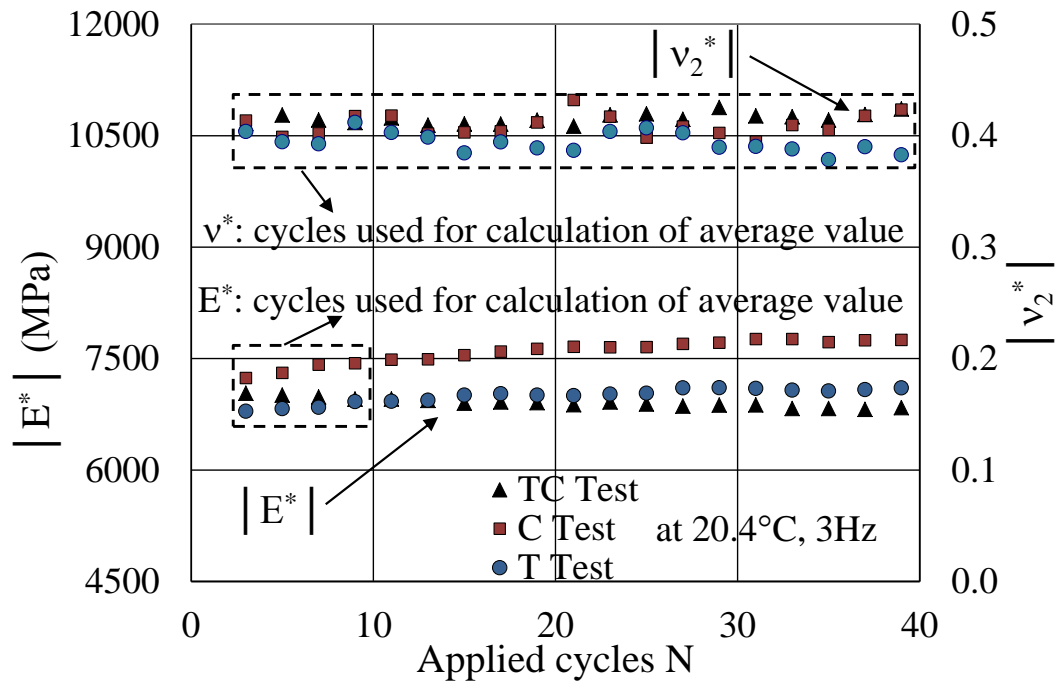

Fig. $6\left|\mathrm{E}^{*}\right|$ and $\left|v_{2}{ }^{*}\right|$ values obtained at $20.4{ }^{\circ} \mathrm{C}$ and $3 \mathrm{~Hz}$ from the 3 loading modes

Fig. 7 presents the $\mathrm{E}^{*}$ master curves (norm and phase angle) at the reference temperature $\mathrm{T}_{\mathrm{ref}}=11.1^{\circ} \mathrm{C}$ for the 3 loading modes. The same shift factor a $\mathrm{a}_{\mathrm{T}}$ was used to plot these master curves. Figures 8 and 9 allow to analyse the difference between the complex moduli obtained with the 3 modes of loading $\left(\mathrm{E}^{*} \mathrm{TC}, \mathrm{E}^{*} \mathrm{~T}\right.$ and $\left.\mathrm{E}^{*} \mathrm{C}\right)$. Considering $\mathrm{E}^{*} \mathrm{TC}$ as reference, Fig. 8 gives the relative difference between the norm of the modulus and Fig. 9 indicates the phase angle difference for $\mathrm{T}$ and $\mathrm{C}$ cases, as a function of reduced frequency. These figures show that above reduced frequency at $11^{\circ} \mathrm{C}$ of about $10^{-1} \mathrm{~Hz}$ (low temperatures/high frequencies), the three $\mathrm{E}^{*}$ values can be considered as identical. Below this value of $10^{-1} \mathrm{~Hz}$, the difference among the 3 moduli becomes more and more important when decreasing equivalent frequencies and reaches $40 \%$ for $\mathrm{C}$ test (20\% for T test) in norm and 7 degrees in phase angle. At high temperatures/low frequencies, the norm of complex modulus (resp. phase angle) from TC test is higher (resp. lower) than the one from $\mathrm{T}$ test and lower (resp. higher) than the one from $\mathrm{C}$ test. Nguyen QT et al. [9] showed that the linearity limit (defined as a relative decrease of 5\% in norm) of bituminous mixtures, which respects time-temperature superposition principle (TTSP), varies with temperature-frequency couples and becomes higher at high frequency (or low temperature). The authors do think the difference observed at high temperature/low frequency is only explained by the non-linearity of the material (i.e. influence of strain amplitude on complex modulus) and accumulated deformation (see section 3.2). If amplitude of applied cycles were lower (which is experimentally not possible with our device) no difference in 
modulus would be obtained in tension and compression. This important result indicates that there is no moduli discontinuity between tension and compression as it is frequently postulated in the literature. The experimental results presented in this paper confirm this result for frequency higher than $0.1 \mathrm{~Hz}$ at $11.1^{\circ} \mathrm{C}$.

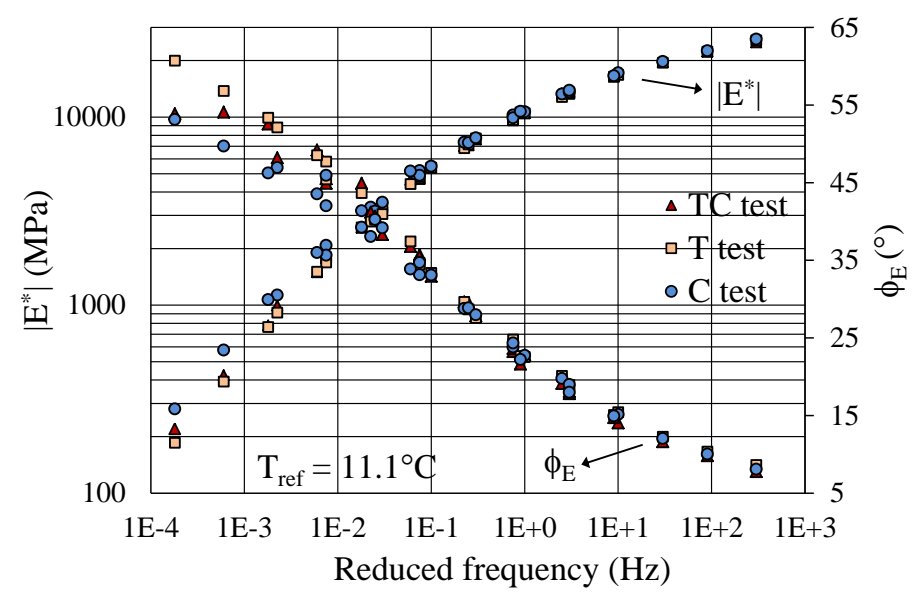

Fig.7 Master curves of $\left|\mathrm{E}^{*}\right|$ and $\phi_{\mathrm{E}}$ at $\mathrm{T}_{\mathrm{ref}}=11.1^{\circ} \mathrm{C}$

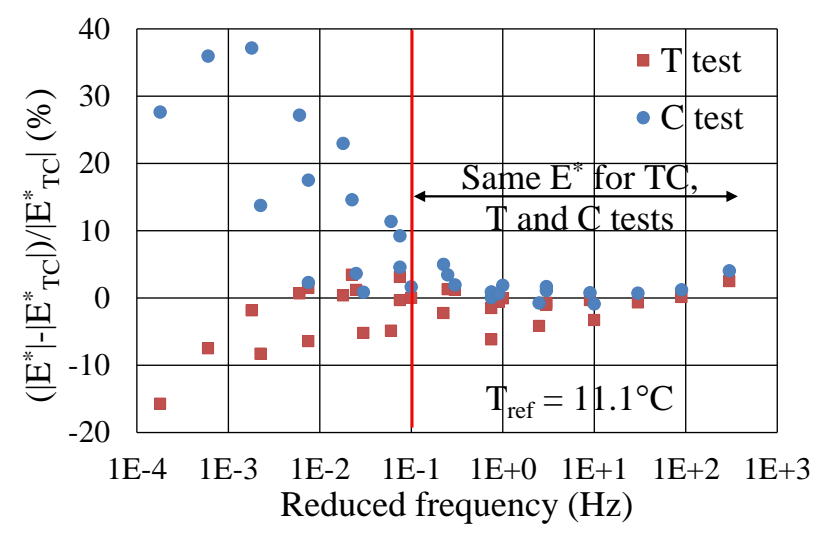

Fig.8 Comparison of $\left|\mathrm{E}^{*}\right|$ values from 3 loading modes

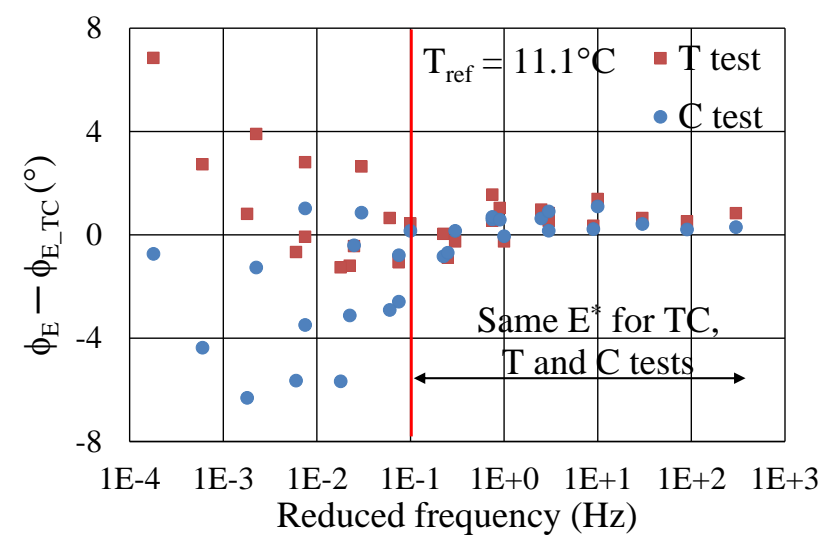

Fig.9 Comparison of $\phi_{\mathrm{E}}$ values from 3 loading modes

Some authors propose to calculate the strain amplitude from the max and min values of the measured sinusoidal data, called "peak amplitude". The peak 
amplitudes, determined in two cases can be considered as explained in Fig. 5: case I (when i = 1) and case II (when i =2). Amplitude obtained from peak values are given in equation 9 where $\max _{i}(i=1,2)$ and min values, are indicated in Fig. 5.

$$
\text { peak amplitude }=\left(\max _{i}-\min \right) / 2
$$

The relative difference of the norm of complex modulus obtained from $\mathrm{T}$ and $\mathrm{C}$ tests in cases I and II, are plotted in Fig. 10. It can be clearly seen that when using the peak amplitudes for analysing $\mathrm{E}^{*}$, a big difference in $\mathrm{E}^{*}$ values can be obtained following the considered case. Difference up to $150 \%$ is reached at low reduced frequency. The observed difference is mainly explained by accumulated deformation that should be eliminated from the analysis, as explained previously.

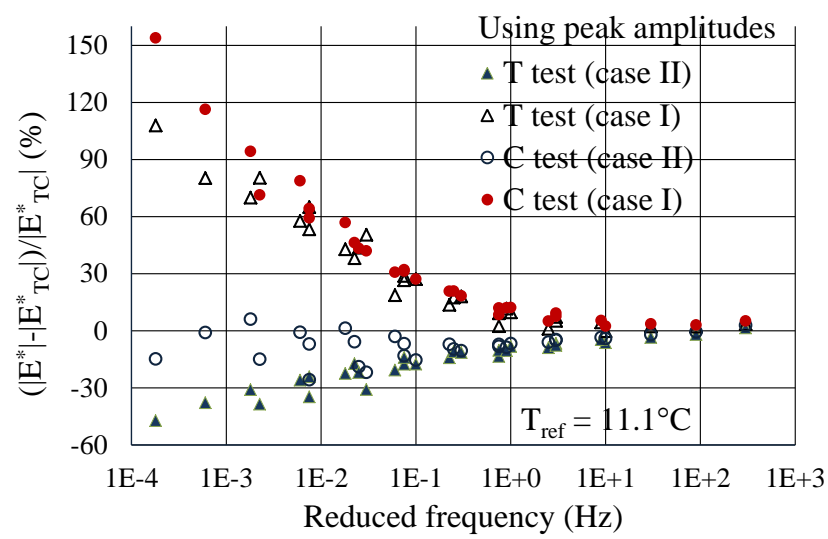

Fig.10 Comparison of $\left|E^{*}\right|$ values obtained using the peak amplitudes (Fig. 5), mistake introduced by accumulated deformation are visible when comparing cases I and II.

The master curves of complex Poisson's ratios are plotted in Fig. 11 (norm) and Fig. 12 (phase angle) using the same shift factor $\mathrm{a}_{\mathrm{T}}$ than the one considered for $\mathrm{E}^{*}$. The values of $\mathrm{a}_{\mathrm{T}}$ at $1.4^{\circ} \mathrm{C}, 11.1^{\circ} \mathrm{C}, 15.8^{\circ} \mathrm{C}, 20.4^{\circ} \mathrm{C}$ and $29.9^{\circ} \mathrm{C}$ are $30,1,0.25$, 0.075 and 0.006 , respectively $\left(\mathrm{T}_{\mathrm{ref}}=11.1^{\circ} \mathrm{C}\right)$. These results confirm the TTSP can be applied in 3D for tested bituminous mixture, which validates results from other studies on bitumen and mastic [10] or on asphalt mixtures [24-27]. The differences in $v^{*}$ values when comparing TC test with $\mathrm{T}$ or $\mathrm{C}$ test are small, especially for $\phi_{v}$ values. It can be observed in Fig. 11 that Poisson's ratio values are slightly different between direction II and III $\left(v_{2}{ }^{*}\right.$ and $\left.v_{3}{ }^{*}\right)$, which denotes a slight anisotropy between the 2 directions. 


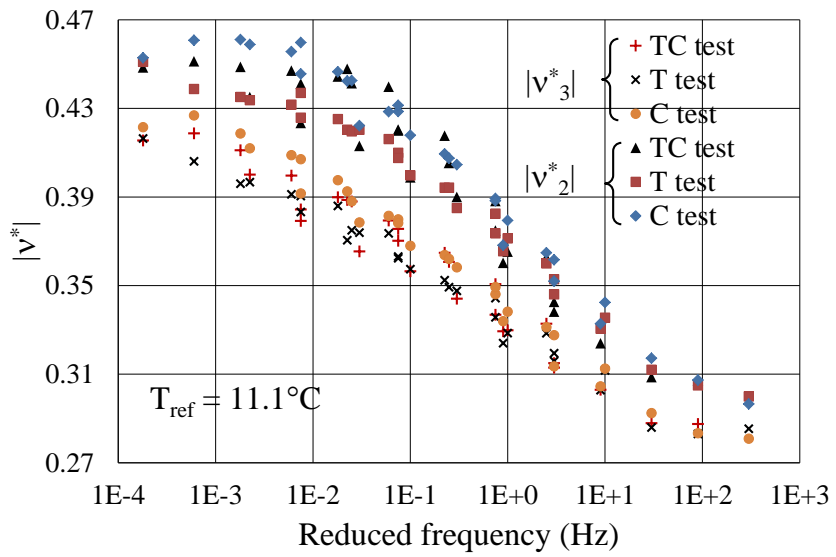

Fig. 11 Master curves of $\left|v^{*}\right|$ at $\mathrm{T}_{\text {ref }}=11.1^{\circ} \mathrm{C}$

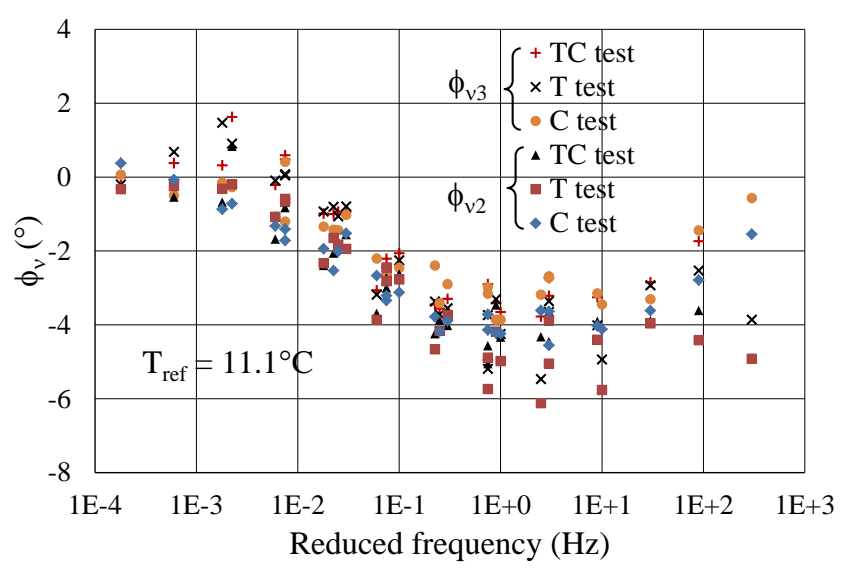

Fig. 12 Master curves of $\phi_{v}$ at $\mathrm{T}_{\text {ref }}=11 \cdot 1^{\circ} \mathrm{C}$

\subsection{Accumulated axial and radial strains}

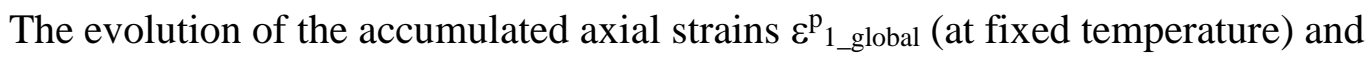
$\varepsilon^{\mathrm{p}_{1}}$ (at fixed temperature and fixed frequency) with number of applied cycles when performing T, C and TC tests at $29.9^{\circ} \mathrm{C}$ is presented in Fig. 13 and Fig. 14,

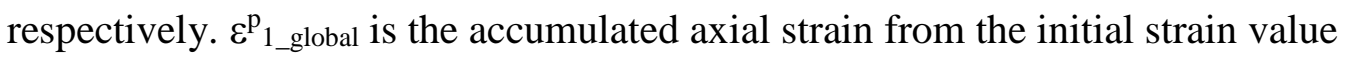
(original point) at a fixed temperature (Fig. 13). $\varepsilon^{\mathrm{p}_{1}}$ is the accumulated axial strain from the strain values at the beginning of each loading for a fixed frequency (Fig. 14). The accumulated axial strain is obviously nil in TC tests, whereas it can reach $0.2 \%$ in $\mathrm{T}$ test and $-0.12 \%$ in $\mathrm{C}$ test (Fig. 14). It is underlined that the axial stress amplitudes $\sigma_{01}$ (see equation 6) applied at each temperature-frequency couple in $\mathrm{T}$ and $\mathrm{C}$ tests are different and are controlled to obtain about $50 \mu \mathrm{m} / \mathrm{m}$ of axial strain amplitude $\varepsilon_{01}$. Fig. 13 shows that even for the "small" number of applied cycles at $29.9^{\circ} \mathrm{C}$, the reached level of accumulated strain is quite higher (more than 200 times) than amplitude strain value. As modulus is probably sensitive to 
contraction or extension value, these high accumulated strain values is one of the phenomena that could explain the observed difference in modulus at high temperature/low frequency. The other phenomenon, which is probably of higher influence, is the non-linearity (influence of strain amplitude) of the material as explained previously (section 3.1).

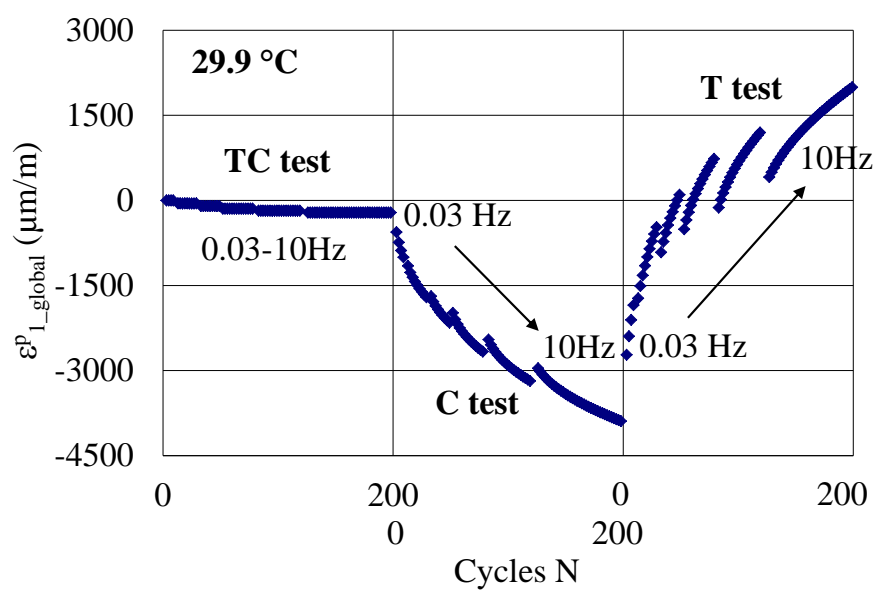

Fig.13 Evolution of the accumulated axial strain $\varepsilon^{\mathrm{p}} 1_{\text {global }}$ in T, C and TC tests at $29.9^{\circ} \mathrm{C}$

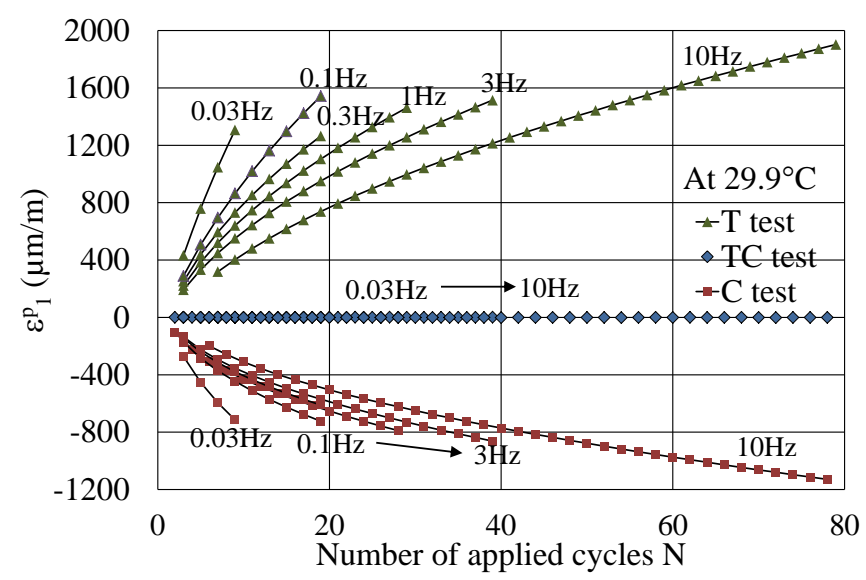

Fig.14 Evolution of the accumulated axial strain $\varepsilon^{\mathrm{p}}{ }_{1}$ in $\mathrm{T}, \mathrm{C}$ and TC tests at $29.9^{\circ} \mathrm{C}$ for each frequency (same data as Fig. 13)

\section{Conclusion}

In this paper, complex modulus tests were performed considering three different loading modes: tension (T), compression (C) and tension-compression (TC). The accurate measurements of stress and strain values gave three dimensional information on bituminous mixture behaviour. From the analysis of results, the following conclusions can be drawn: 
- The complex modulus $E^{*}$ and the complex Poisson's ratio $v^{*}$, respect the TTSP with the same shift factor, as already stated by other studies.

- In case of $\mathrm{T}$ tests and $\mathrm{C}$ tests, the accumulated axial and radial strains, which can be up to $0.2 \%$ in tension and $0.12 \%$ in compression at $29.9{ }^{\circ} \mathrm{C}$, is much higher than strain amplitude and cannot be neglected when analysing the data. In particular, peak to peak analysis must not be used to obtain norm of modulus values.

- $\quad \mathrm{E}^{*}$ values obtained from the 3 loading modes are similar for average and low temperatures. At high temperature differences up to $40 \%$ in norm and $7^{\circ}$ in phase angle were obtained. This difference could be explained by important accumulated deformation and nonlinearity. In case of using the peak amplitude to calculate the norm of modulus, this difference can be up to $150 \%$.

- $\quad$ Poisson ratio values were very close for the 3 loading modes. A small anisotropy could be noticed from this parameter between directions 2 and 3 .

From presented results, the developments considering different modulus values in tension and compression, as sometimes proposed in the literature, does not seem to correspond to material behaviour and should be revised.

\section{Acknowledgements}

This research is funded by Vietnam National Foundation for Science and Technology

Development (NAFOSTED) under grant number 107.02-2014.22.

\section{References}

[1] Francken L, Partl M and Technical Committee on Bitumen and Asphalt Testing (1996)

Complex Modulus Testing of Asphaltic Concrete: RILEM Interlaboratory Test Program.

Transportation Research Record, Vol.1545, pp. 133-142

[2] Witczak MW, Bonaquist R, Von Quintus H, and Kaloush K (2000) Specimen Geometry and Aggregate Size Effects in Uniaxial Compression and Constant Height Shear Tests. Proceedings, Association of Asphalt Paving Technologists, Vol. 69, pp. 733-793

[3] Di Benedetto H, Partl MN, Francken L and De la Roche C (2001) Stiffness testing for bituminous Mixtures. Materials and Structures, Vol.34, pp. 66-70

[4] Kallas BF (1970) Dynamic Modulus of Asphalt Concrete in Tension and Tension-Compression and Discussion. Proceedings, Association of Asphalt Paving Technologists, Vol 39, pp 1-23

[5] Khanal PP, and Mamlouk MS (1995) Tensile Versus Compressive Moduli of Asphalt

Concrete. Transportation Research Record, Vol. 1492, pp. 144-150 
[6] Airey G, Rahimzadeh B and Collop A (2003) Viscoelastic linearity limits for bituminous materials. 6th International RILEM Symposium on Performance Testing and Evaluation of Bituminous Materials, Zurich, pp. 331-338

[7] Di Benedetto H, Olard F, Sauzéat C, Delaporte B (2004) Linear viscoelastic behavior of bituminous materials: from binders to mixes. Road Materials and Pavement Design, Vol.5, Special Issue, pp. 163-202

[8] Delaporte B, Di Benedetto H, Chaverot P, Gauthier G (2007) Linear Viscoelastic Properties of Bituminous Materials: from Binders to Mastics. Journal of the Association of Asphalt Paving Technologists, $34 \mathrm{p}$.

[9] Nguyen QT, Di Benedetto H, Sauzéat C (2015) Linear and nonlinear viscoelastic behaviour of bituminous mixtures. Materials and Structures, Volume 48, Issue 7, pp. 2339-2351

[10] Di Benedetto H, Delaporte B and Sauzéat C (2007) Three-dimensional linear behavior of bituminous materials: experiments and modeling. International Journal of Geomechanics (ASCE), 7 (2), 149-157

[11] Di Benedetto H, Sauzéat C and Sohm J (2009) Stiffness of bituminous mixtures using ultrasonic waves propagation. Road Materials and Pavement Design, 10 (4), 789-814

[12] Delaporte B, Di Benedetto H, Chaverot P, Gauthier G (2009) Linear viscoelastic properties of bituminous materials including new products made with ultrafine particles. Road Materials and Pavement Design, 10(1), 7-38

[13] Nguyen QT, Di Benedetto H, Sauzéat C, Tapsoba N (2013) Time Temperature Superposition Principle Validation for Bituminous Mixes in the Linear and Nonlinear Domains. Journal of Materials in Civil Engineering, Vol. 25 (Issue 9), pp 1181-1188

[14] Baaj H, Ech M, Tapsoba N, Sauzéat C, Di Benedetto H (2013) Thermomechanical characterization of asphalt mixtures modified with high contents of asphalt shingle modifier (ASM®) and reclaimed asphalt pavement (RAP). Materials and Structures, Volume 46, Issue 10, pp 1747-1763, doi: 10.1617/s11527-013-0015

[15] Mangiafico S, Di Benedetto H, Sauzeat C, et al. (2013) Influence of reclaimed asphalt pavement content on complex modulus of asphalt binder blends and corresponding mixes: experimental results and modelling. Road Materials and Pavement Design, Volume 14, SI, pp 132-148

[16] Mounier D, Di Benedetto H, Sauzeat C (2012) Determination of bituminous mixtures linear properties using ultrasonic wave propagation. Construction and Building Materials, Volume 36, pp 638-647

[17] Gudmarsson A, Ryden N, Di Benedetto H et al. (2014) Comparing Linear Viscoelastic Properties of Asphalt Concrete Measured by Laboratory Seismic and Tension-Compression Tests. Journal of Nondestructive Evaluation, Volume 33, Issue 4, pp. 571-582

[18] Gudmarsson A, Ryden N, Di Benedetto H et al. (2015) Complex modulus and complex Poisson's ratio from cyclic and dynamic modal testing of asphalt concrete. Construction and Building Materials, Volume 88, pp 20-31 
[19] Chehab GR, Kim YR, Schapery RA, Witczak MW, Bonaquist R (2002) Time-Temperature superposition principle for asphalt concrete mixtures with growing damage in tension state. $\mathrm{J}$ Asph Paving Technol, 71:559-593

[20] Schwartz CW, Gibson N, Schapery RA (2002) Time-temperature superposition for asphalt concrete at large compressive strains. Transp Res Rec 1789:101-112

[21] Zhao Y and Kim YR (2003) Time-temperature superposition for asphalt mixtures with growing damage and permanent deformation in compression. Transp Res Rec 1832:161-172 [22] Nguyen H M, Pouget S, Di Benedetto H, Sauzéat C (2009) Time-Temperature Superposition Principle for bituminous mixtures. European Journal of Environmental and Civil Engineering, pp. 1095-1107

[23] Nguyen M L, Sauzéat C, Di Benedetto H, Tapsoba N (2013) Validation of the TimeTemperature superposition principle for crack propagation in bituminous mixtures. Materials and Structures, Volume 46, Issue 7, pp 1075-1087, DOI 10.1617/s11527-012-9954-7

[24] Pham NH, Sauzéat C, Di Benedetto H, Gonzalez-Leon JA, Barreto G, Nicolai A, Jakubowski M (2015) Reclaimed Asphalt Pavement and additives influence on 3D linear behaviour of warm mix asphalts. Road Materials and Pavement Design, Vol. 16, Issue 3, pp. 569-591, doi 10.1080/14680629.2015.1021108

[25] Pham NH, Sauzéat C, Di Benedetto H, Gonzalez-Leon JA, Barreto G, Nicolai A, Jakubowski M (2015). Analysis and modeling of 3D complex modulus tests on hot and warm bituminous mixtures. Mechanics of Time Dependent Materials, Vol. 19 - 2, pp. 167-186, DOI: $10.1007 / \mathrm{s} 11043-015-9258-8$

[26] Perraton D, Di Benedetto H, Sauzéat C, Hofko B, Graziani A, Nguyen QT, Pouget S, Poulikakos LD, Tapsoba N, Grenfell J (2016) 3Dim experimental investigation of linear viscoelastic properties of bituminous mixtures. Materials \& Structures, Volume 49, Issue 11, pp 4813-4829, DOI 10.1617/s11527-016-0827-3

[27] Graziani A, Di Benedetto H, Perraton D, Sauzéat C, Hofko B, Poulikakos LD, Pouget S (2017) Recommendation of RILEM TC 237-SIB on complex Poisson's ratio characterization of bituminous mixtures", Materials \& Structures (accepted)

[28] Association Française de Normalisation (AFNOR) (2007) Bituminous mixtures-Test methods for hot mix asphalt_-Part 33: Specimen prepared by roller compactor. EN 1269733:2003+A1:2007

[29] Di Benedetto H, Nguyen QT and Sauzéat C (2011) Nonlinearity, Heating, Fatigue and Thixotropy during Cyclic Loading of Asphalt Mixtures. Road Materials and Pavement Design, Vol.12 ( $\left.\mathrm{N}^{\circ} 1\right)$, pp 129-158

[30] Nguyen QT, Di Benedetto H and Sauzéat C (2012) Determination of Thermal Properties of Asphalt Mixtures as Another Output from Cyclic Tension-Compression Test. Road Materials and Pavement Design, Vol.13 ( $\left.{ }^{\circ} 1\right)$, pp 85-103

[31] Nguyen QT, Di Benedetto H, Sauzéat C (2015) Effect of fatigue cyclic loading on linear viscoelastic properties of bituminous mixtures. Journal of Materials in Civil Engineering, Volume 27, Issue 8, 10.1061/(ASCE)MT.1943-5533.0000996 
[32] Gayte P, Di Benedetto H, Sauzéat C, Nguyen QT (2016) Influence of transient effects for analysis of complex modulus tests on bituminous mixtures. Road Materials and Pavement Design, Vol.17 Issue: 2, pp 271-289 